\title{
Experiências em Missão de Estudos Procad: troca de conhecimentos em design
}

Samuel da Silva Miranda;

Denilson Moreira Santos

\section{Resumo:}

Este artigo traz um relato de experiência, sobre a participação em missão de estudos, por meio do projeto Procad/AM, relacionado a difusão do conhecimento no campo do design. Neste sentido, envolve-se reflexões sobre a relação entre design e comunidades criativas (artesanato), foco das abordagens do referido projeto e consequentemente da missão de estudos, efetivada nas instituições associadas, no caso, a Escola de Design da Universidade do Estado de Minas Gerais - ED/UEMG. Logo, inicialmente apresenta-se reflexões acerca do estabelecimento relacional entre os campos design-artesanato e o posicionamento do designer, imerso nos contextos das comunidades tradicionais. O percurso da missão de estudos na ED/UEMG, envolveu participação em disciplinas e eventos da área, revisão de literatura, parceria com centros de pesquisa e efetivação de pesquisa de campo. Antecipa-se que, os resultados dessa interação, enriqueceram experiências do discente em missão, aprofundando conhecimentos, ampliando oportunidades, estabelecendo futuros possíveis sobre pesquisa, caminhos profissionais e da ciência.

Palavras-chave: Design; Artesanato; Procad/AM; Interação 


\section{A importância do tema}

O artigo aqui proposto, objetiva apresentar experiências vividas em missão de estudos, por meio de um projeto do Programa Nacional de Cooperação Acadêmica na Amazônia - Procad/AM, promotor da difusão do conhecimento em design, sobretudo nas relações entre designers e comunidades criativas. Entende-se, para o referido projeto, que o designer, mediante a um cenário relacional entre saberes especializados e tácitos (SPINUZZI, 2005), deve assumir o posicionamento de mediador de processos, especialmente nas caracterizações que se apresentam entre o design-artesanato. Logo, abordar primeiramente a relação entre os dois campos, se mostra importante, no intento de evidenciar as conjunturas que se estabelecem e o percurso, dessa relação, trilhado através da história. Para além, importa o enfoque sobre essa discussão para o Procad/AM e consequentemente para o discente em missão de estudos, devido a sua significância teórico-científico.

Deste modo, em um panorama brasileiro, a discussão sobre a relação entre design-artesanato, advém desde a chegada de Aloísio Magalhães no comando do Instituto do Patrimônio Histórico e Artístico Nacional-IPHAN na década de 1990 (Noronha, et al., 2015). Desde então, observa-se que as reflexões sobre artesanato e design, bem como a integração desses dois campos de saberes, vem sendo cada vez mais difundidas. Esse fato é reforçado na perspectiva de Almeida (2013), ao afirmar que são numerosos os exemplos relacionais entre o design e artesanato, revelando um movimento constante, existente sobre essas abordagens, além de suscitar possíveis impactos no âmbito social e econômico.

Essa relação vem passando por constantes debates, devido influências de momentos históricos e pelas reflexões a respeito da dissociação e reaproximação desses saberes. Sobre isso, sabe-se que o design perpassou na história, um momento importante, promovido pelo pensamento da produção industrial e consequente consumismo, alavancado principalmente pelo amplificado efeito pós Revolução Industrial. A sociedade, portanto, foi aderindo a um modelo de design que atendesse desejos, resoluções de problemas e criação de novos objetos. Ribeiro (2014) reflete sobre o assunto, ao afirmar que justamente a Revolução Industrial se tornou um marco no princípio da produção em esfera global, com características relacionadas ao fortalecimento do capitalismo, aumento da produção e da produtividade, dilatando na sociedade um comportamento para o moderno e/ou contemporâneo, atenuando mudanças nos estilos de vida, e na geração do lucro, a partir do aumento do consumo.

Desde então, ao longo do tempo esses anseios do "modernizar-se" promoveu fluxos que resvalaram no design e em sua relação originária com o artesanto. Porém, não é o objetivo aqui refletir sobre as origens do artesanato e do design, nem seus conceitos evoluídos ou em evolução, mas refletir a respeito das relações de hierarquia de conhecimento (SANTOS, 1989) e de poder (SPINUZZI, 2005) dentro das relações entre os campos de saberes. Possivelmente, o pensamento do designer de solucionador de problemas, advém da mentalidade pós revolução, pois os especializados, neste caso os designers, eram então, considerados aqueles que detinham informações, suficientes para promover e/ou adequar os modos de produção em detrimento de problemas, encontrados nos processos formais/industriais.

Percebe que esse posicionamento, excita um divórcio entre o conhecimento especializado (designers) e o tácito (artesãos), sendo este último, por vezes considerado inferior. No entanto, como característica marcante da produção artesanal, tem-se a forte integração entre a manualidade e a intelectualidade, perspectiva contrária a produção na indústria, onde no princípio da divisão social, se estabelece as instâncias do trabalho e das especializações de forma separadas (LIMA, 2015). Logo, houve um posicionamento elitista relacionado a atuação do designer, e suas configurações, dentre eles o papel estabelecido do projetar (ARGAN, 1993), está, em uma visão moderna, se instituindo como superior.

Ainda para Lima (2015), é urgente discutir as relações dominantes, pois é necessária a compreensão de que o artesanato é pautado nas relações heterogêneas, vivenciadas no complexo e na diversidade, situações que geram reflexos perante as dimensões socioculturais e econômicas, postas em uma sociedade contemporânea. $\mathrm{O}$ artesanato é um meio de forte expressão cultural, não apenas alicerçado pela tradição, na perspectiva de passado, ou ultrapassado, ou mesmo sentenciado ao desaparecimento, na verdade é uma ação do hoje pela construção do ontem que constituem alterações legítimas a partir dos grupos que detém esses saberes tácitos. 
As experiências da relação entre design e artesanato, foram sendo construídas em diversos estudos, processos, metodologias e práticas. Entretanto, algumas "armadilhas" como apresenta Portela (2018) do restabelecimento dessa relação, devem ser observadas e desarmadas, principalmente quando o design se mostra intervencionista nos processos tácitos do artesanato. Essa atitude interventora, segundo Borges (2011), é manifestada por diversos exemplos da atuação do designer, e, geralmente, os mesmos, se colocam como superiores aos artesãos, apenas por apresentar especialidades, atitude que reforça um posicionamento elitistas do design.

Enfim, percebe-se que há uma necessidade de entendimento, relativos a essa relação designartesanato, onde o profissional designer precisa estabelecer quebras hierárquicas, geradas ao longo da história, como abordado por Santos (1989), Spinuzzi (2005) e Binder (2011), autores que conversam a respeito dessas relações e quebras paradigmáticas e epistemológicas, conexos aos saberes, que, mesmo em suas diferenças, são estabelecimentos de apreensões, experiências, vivências e convivências, construídos ao longo de investimentos históricos e geracionais, além de teóricos e práticos. Sobre a atuação do design no artesanato, não necessariamente se refuta essa relação, mais importa ao design a compreensão de que "as necessidades e características da sociedade de hoje pedem aos designers uma atuação diferente do passado" (GAUDIO; OLIVEIRA; FRANZATO, 2014, p. 6).

Como afirma Miranda (2019), o designer precisa estar atento ao seu posicionamento frente a atuação em conjunto com artesãos, pois sua colocação não mais se apresenta no centro do processo, como demonstrado na geração moderna, pois essas característica define o designer como um gestor interventor, estabelecendo uma superposição especializada em detrimento da tácita, ou seja, o designer deve dar a atenção às subjetividades de cada atuante nos processos, colocando em posição de evidências, não apenas um, mais todos os agentes sociais para o protagonismos das práticas. Desta forma, corroborando com Noronha $(2012$, p.8) o design mover-se "do centro dos processos para o meio deles, [...], como uma estratégia de melhor nos alfabetizarmos na linguagem do outro".

A linguagem do design, portanto, deve se transformar para um significado mais relacional, capaz de promover a melhor compreensão do seu papel, sendo este, objetivado pela imersão ou mesmo mistura das ações, ainda ciente das diversidades, presente nos âmbitos dos diferentes saberes, de forma a promover um movimento agregador de saberes e de fazeres, não instituindo pesos hierárquicos e fronteiras do saber (MIRANDA, 2020).

É neste sentido, que a colaboração do projeto Procad/AM, foco da apresentação desta comunicação, vem se debruçar, pois, objetiva-se com ele, ressaltar a importância dos conhecimentos tácitos em comunidades criativas, trabalhando na relação que se estabelece entre design e saberes locais a partir do posicionamento do designer, caracterizado como mediador de processos. O projeto importa para essa temática, pois as experiências vividas em missão, consideraram a percepção e aproximação de saberes entre o design e o artesanato, encontrado na ED/UEMG e na cidade de Belo Horizonte - MG em si, além de possível observação de projetos e pesquisas futuras, que possam promover um comportamento mais relacional, através de estudos oriundos das instituições associadas.

Sobre os projetos Procad, de um modo geral, cabe destacar a importância e impactos na formação e experiência de discentes e docentes nas diversas áreas de conhecimento em que foram ou estão sendo contemplados com essas possibilidades de troca. O Procad, objetiva a formação de pesquisadores e a promoção de conhecimento científico e tecnológico, interligadas a estudos promovidos em conjunto em um médio período de duração (MOURA, 2016), além de fortalecer, o intercâmbio científico no país, envolvendo equipes acadêmicas de múltiplas instituições de ensino superior e de pesquisa, possibilitando a elevação geral da qualidade do ensino superior e da pósgraduação (CAPES, 2018).

Dentro dos projetos inseridos nos objetivos do Procad, o Programa Acelera Amazônia, criado no ano de 2006, objetivou ações no tentame da diminuição das desigualdades e das assimetrias educativas, sobretudo no ensino superior e nas pós-graduações regionais. Buscando a conquista desses objetivos, o subprograma Procad/AM foi instituído, objetivando o apoio da qualificação de discentes e docentes para a geração de conhecimento em conjunto, interligando os intercâmbios e promovendo a manutenção de doutores na região da Amazônia (MOURA, 2016). Denota-se a importância do estabelecimento dessas relações, pois a troca de experiências, a observância das pesquisas, desenvolvidas nas diferentes instituições associadas aos projetos, bem como o crescimento acadêmico e profissional de professores e alunos, são consequências positivas da experiência do Procad, neste caso do Procad/AM. 
Enfim, os fatores que fomentam a importância de discutir e apresentar esse tema, é observado pelo desejo do melhor restabelecimento das relações entre os diferentes atores sociais, designersartesãos, imersos em cenários, historicamente importantes, além da discussão sobre as formas de interlocução entre esses diferentes saberes e o fomento das experiências, que são advindas de projetos possíveis, como o Procad/AM. Esses fatores, reúnem importante reflexão sobre as ampliações das vivências e aprendizados na execução de projetos como esse, que fazem emergir pensamentos a respeito da efetivação dessas experiências com o cenário atual em que o Brasil e o mundo se encontra.

Vivemos, então, atualidades complexas, sobretudo devido ao enfrentamento da humanidade quanto a nova pandemia de coronavírus, a Covid - 19. Essa manifestação epidemiológica, se manifesta, contrariando as normalidades da sociedade à época. Logo, pensar em aproximações e experiências presenciais, é um "normal" que já não se apresenta possível, devido a expressiva força da contaminação desse novo mal. As experiências, no hoje, com artesãos e entre eles, não se configura como movimento seguro na perspectiva da saúde coletiva e das comunidades, portanto, metodologicamente, projetos Procad e todo e qualquer percurso, que envolve presenças físicas e o estabelecimento de relações presenciais próximas, são postas como práticas atuais, contrárias às recomendações das organizações e associações globais para com a sociedade em geral.

A comunicação que aqui se apresenta, expõe experiências vividas em missão de estudos na ED/UEMG, pelo Procad/AM no primeiro semente -Abril/Agosto- de 2019. Momento no qual a pandemia ainda estava apenas no imaginário "hollywoodiano" do senso comum, no entanto, tempos depois, constatou-se que essa realidade já se apresentava. Este artigo, se revela como um documento que poderá apresentar experiências de um período, chamado aqui de "pré-pandemia", escrito em meio a própria pandemia e que promoverá possivelmente, futuras consultas sobre essas experiências no "pós pandemia", configurando-se assim, um documento provável para a compressão dos impactos causados pela Covid-19, neste momento da história. Deste modo, indaga-se: como seria a vivência da missão de estudos, se esta ocorresse, em sua instância, no olho do furacão (Pandemia de Covid-19)? Após a apreciação do relato de experiência, as discussões retomarão essa abordagem.

\section{Processos das experiências e vivências no Procad/AM}

Este artigo apresenta um relato de experiências da missão de estudos, realizada pelo projeto Procad/AM, com o título PROCAD-COMUNIDADES CRIATIVAS E SABERES LOCAIS: Design no contexto social e cultural de baixa renda. Destaca-se, que o referido projeto, envolve docente coordenador e representantes docentes das instituições proponente e associadas. Contudo, este relato trata das experiências concretizadas pela participação do primeiro autor desse artigo, como discente membro em missão de estudos e o segundo autor, como seu orientador de mestrado e consequentemente da própria missão.

Este projeto possui como proponente o Programa de Pós-Graduação em Design da Universidade Federal do Maranhão-PPGDg/UFMA, como primeira instituição associada a Universidade do Estado de Minas Gerais, por meio de sua Escola de Design - ED/UEMG e a Universidade Federal do Paraná-UFPR como segunda instituição associada. Ambas as instituições participam por meio de seus programas de pós-graduação em design.

A experiência da missão de estudos, foi concretizada na primeira instituição associada, ED/UEMG, na cidade de Belo Horizonte - MG, entre os dias 04 de abril de 2019 a 04 de agosto do corrente ano. $\mathrm{O}$ foco das atividades, consideraram a efetivação da participação em disciplinas isoladas, revisão da literatura, está sendo concentrada em design e materiais, cerâmica e processos artesanais de produção, participação em eventos, atuação em centros de pesquisa e pesquisas de campo, além de outras atividades ligadas à programação estabelecida para o período de quatro meses. A instituição anfitriã, forneceu toda a infraestrutura para a realização das atividades, além da estreita colaboração de técnicos, docentes e discentes da pós-graduação da ED/UEMG.

Esse relato, apresenta abordagens ligadas às interlocuções e conhecimento, a respeito da relação design-artesanato, objetivando o estabelecimento de trocas de saberes e vivências com artesãos mineiros, com as próprias experiências do pesquisador em missão, relativos ao artesanato do estado do Maranhão. Aprofundando ainda mais as buscas por estudos, ligados às relações entre os dois campos de saberes, design-artesanato, a produção artesanal em cerâmica é assumida como foco. Buscou-se o 
conhecimento das práticas artesanais, encontradas em Minas Gerais em relação as experiências do artesanato cerâmico do estado do Maranhão.

Para isso, as pesquisas de campo, efetuadas em Belo-Horizonte, foram de fundamental importância para o estabelecimento dos resultados obtidos na missão. A busca por literaturas na área do design, que apresentam abordagens em design, artesanato e produção artesanal em cerâmica, foram significativas para a percepção de como as pesquisas sobre o tema é desenvolvida nas duas regiões. Os eventos científicos auxiliaram na apresentação das pesquisas, tanto na pesquisa de mestrado, então em construção pelo discente em missão, quanto na difusão dos conhecimentos sobre a temática abordada e vivenciada. Para além, as disciplinas isoladas cursadas na ED/UEMG no período letivo regular da instituição, forneceram bases teóricas importantes para o aprimoramento e aprofundamento da dissertação de mestrado desenvolvida, além da ampliação dos conhecimentos em design, história, materiais, cerâmica, processos, sustentabilidade e metodologia em design.

Por fim, houve uma intensa relação com os centros de pesquisa da graduação e pós-graduação em design da ED/UEMG. As parcerias com os centros, abriram caminhos para novos entendimentos e propostas de pesquisas e relações com docentes e discentes, além do conhecimento das pesquisas, promovidas pelos centros, em vigência à época.

\section{A experiência e vivência da missão}

Inicialmente a possibilidade da participação no projeto Procad/AM, foi apresentada pelos docentes da instituição proponente, envolvidos no projeto, onde, após o aceite do convite, por parte do discente, foram promovidos reuniões preparatórias, ainda na capital maranhense, São Luís - MA. A chegada na capital mineira, Belo Horizonte - MG, no dia 4 de abril de 2019, com a recepção presencial pela Profa. Dra. Nadja Maria Mourão, professora da graduação em design da ED/UEMG, possibilitou expectativas positivas sobre a experiência. Destaca-se a cordialidade e excelente recepção de todos os docentes da instituição anfitriã, sobretudo os docentes e discentes da Pós-Graduação da ED/UEMG.

\subsection{As disciplinas e suas contribuições}

O início efetivo das atividades na ED/UEMG se deu a partir do dia 08 de abril de 2019, com a recepção e apresentação como aluno em missão de estudo ao Programa de Pós-graduação em Design da escola. Após a apresentação, iniciou-se a semana intensiva de aulas da disciplina denominada de História Social do Design no Brasil, onde participou-se especificamente do Módulo II que foi ministrado pelo docente convidado, Prof. Dr. Marcos Braga da Universidade de São - USP. A disciplina realizou-se na modalidade intensiva entre os dias 08 ao dia 12 de abril de 2019. Logo, nesta primeira semana a atenção voltou-se para essas aulas, contribuindo para o aprofundamento sobre o tema da história do design no Brasil.

A disciplina objetivou a exposição de abordagens relativas às primeiras instituições de ensino do design no país, perpassando todos os caminhos percorridos na área do design até o cenário atual, com a diversidade do campo, por meio da multidisciplinaridade e transdisciplinaridade em que o design está imerso na atualidade. Outra participação do discente em missão, foi efetivada pelo convite à participação em aula, na graduação em design, sobre Design Sistêmico, ministrada pelo Profa. Dra. Kátia Pêgo da ED/UEMG. Na ocasião, houve reflexões sobre a epistemologia e hermenêutica referente ao design sistêmico, além da apresentação de projetos que envolvem as abordagens metodológicas do campo.

Concluindo sobre as contribuições oriundas das matérias vivenciadas, a disciplina denominada Materiais Ecoeficientes foi cursada por completo (Figura 01), ou seja, em regime regular, pois houve matrícula prévia e homologação pelo PPGD da ED/UEMG. Essa disciplina foi escolhida para a participação, por apresentar abordagens que auxiliam no referencial teórico-metodológico da pesquisa de mestrado do discente em missão de estudos. A disciplina foi conduzida nas quintas-feiras no turno vespertino, pela Profa. Dra. Rosemary Bom Conselho Sales. 
Figura 01: Participação na disciplina Materiais Ecoeficientes

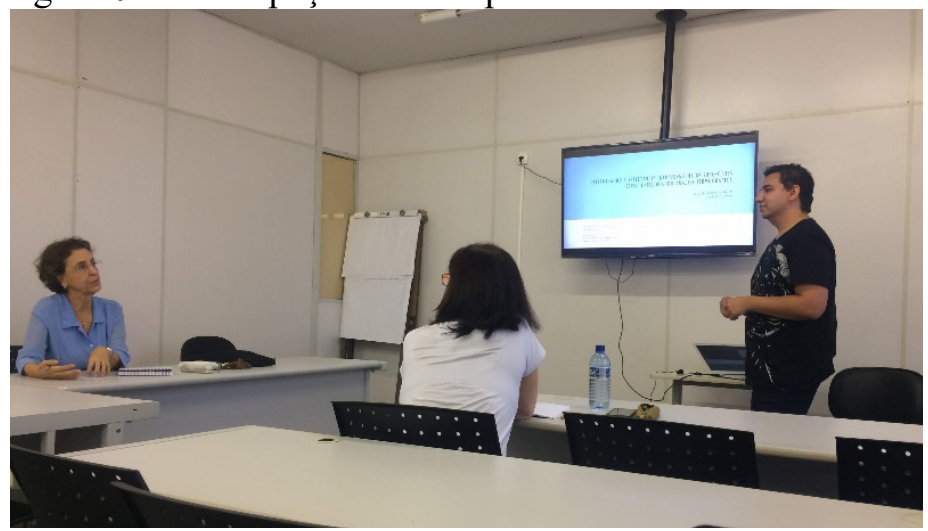

Fonte: Elaborado pelo autor (2019)

A participação nas disciplinas, trouxeram bases reflexivas sobre o design e suas correlações com outros campos de conhecimento, bem como fomentar a progressão da pesquisa de dissertação em desenvolvimento. Destaca-se, a importância da relação objetivada na missão, design-artesanato, sendo a todo momento trazido ao primeiro plano nas discussões. Estabelecer aprofundamentos sobre o trajeto social do design, as novas abordagens do campo, como apresentado no conhecimento do design sistêmico, e as explanações sobre materiais sustentáveis, que contribuíram para a compreensão das relações que se estabelecem nas vivências entre o design-artesanato, ou seja, as visões especializadas (design) que podem ser congregadas nas instâncias do conhecimento tácito (artesanato).

\subsection{Revisão da Literatura: uma busca pelo artesanato cerâmico mineiro}

Revisar a literatura foi considerada uma atividade importante para o conhecimento de temas específicos, sobretudo a respeito do que se objetivou encontrar, sobre artesanato, processos, materiais e cerâmica e suas correlações com o design, por meio da busca de artigos, dissertações, teses e livros. Para além, a revisão da literatura, proporcionou conhecimento relacionados aos temas das disciplinas cursadas em missão de estudos, construção de artigos científicos para submissão em eventos e congressos, além da própria colaboração do arcabouço teórico da dissertação em construção. Esse investimento foi extremamente importante, pois pode-se ter acesso a outras pesquisas, nacionais e internacionais, que contribuíram para a fundamentação teórica.

Um importante recurso para a efetivação dessa revisão, foi a biblioteca da ED/UEMG, por apresentar um grande e importante acervo, que proporcionou a conquista de textos e o acesso aos mais diversos livros a respeito dos temas buscados, bem como a disponibilização do acervo online das publicações da escola, nos níveis da graduação e pós-graduação em design. Além dos livros que o PPGD da ED/UEMG presenteou o discente em missão (Figura 02), que somaram para o aprofundamento das teorias em estudo. Essa atividade metodológica, além de fornecer importantes avanços na elaboração de artigos, auxiliou na construção do trabalho final da disciplina de Materiais Ecoeficientes, cursado regularmente na ED/UEMG, além de colaborar com a escrita da teoria e metodologia da dissertação.

Figura 02: Livros ganhos pelo PPGD da ED/UEMG

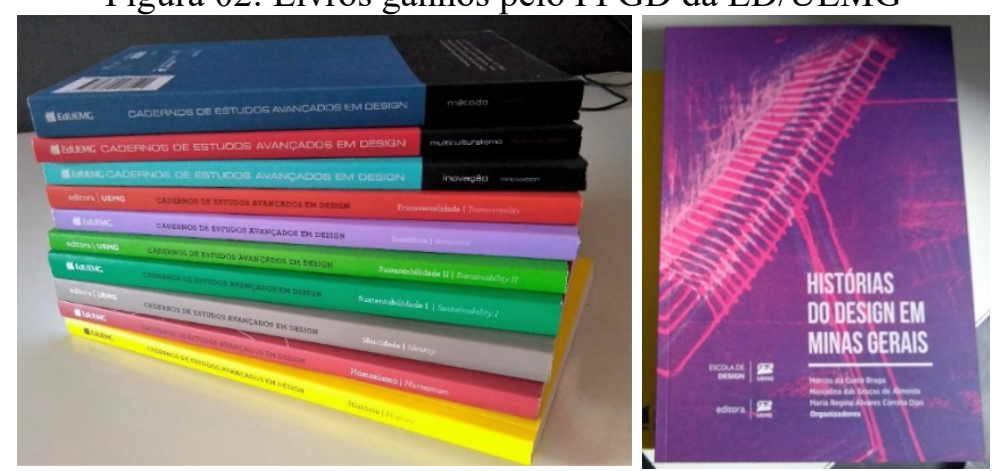

Fonte: Elaborado pelo autor (2019) 
Encontrou-se pesquisas, que levaram ao conhecimento de uma das mais importantes regiões em produção artesanal em cerâmica do país, o Vale do Jequitinhonha-MG. Lugar de cultura pulsante e muitas histórias que já foram contadas e que ainda estão a ser desvendadas. Artesãos, mestres por seus ofícios, detentores de conhecimentos vivos, que produzem peças com os mais diversos significados, valores e identidades, para seus povos e região. Deste modo, as correlações com os polos produtores de cerâmica artesanal no Maranhão, foram acontecendo, por meio da teoria, e as contribuições da revisão se configuraram importantes para o enriquecimento dos trabalhos, então em construção.

\subsection{Participação em Eventos}

O intercâmbio promovido pelo projeto Procad/AM, estimulou a participação em eventos e congressos de design. Nos primeiros meses da missão, houve a oportunidade da participação em uma conferência sobre as experiências do, então professor aposentado da ED/UEMG, Prof. Dr. Jairo Drummond, cujo o tema foi "Jairo Unpluggel: Design, Brands e Autoestima".

$\mathrm{O}$ evento expôs as experiências em projetos e orientações de alunos pelo professor, encaminhados para o mercado nacional e internacional e os prêmios recebidos, por meio dos projetos, como forma de encorajar novos designers a alcançar objetivos maiores na carreira. Uma observação importante a relatar e a excelente recepção, pelo professor Jairo, na apresentação do mestrando pesquisador em missão de estudos da UFMA e no encorajamento para uma atuação como designers, seja na carreira acadêmica ou não. Na ocasião da conferência o discente em missão, pôde relatar, para o público presente, seus objetivos quanto sua missão na ED/UEMG, sendo que a relação designartesanato foi evidenciada pelos estudos em cerâmica e suas práticas tácitas. Um momento de reflexão foi originado, em sequência, sobre a importância do desenvolvimento de pesquisas e metodologias em design que fomentam uma aproximação entre os campos, verdadeiramente respeitosa e que apreenda sobre a valorização do que é tradicional.

Em missão, o pesquisador discente, organizou e participou da Primeira Jornada do Programa de Pós-Graduação em Design da UFMA, evento que sediou o Seminário Procad-1 JopDesign e Seminário Procad. O evento foi realizado em na cidade universitária da UFMA em São Luís - MA e oportunizou apresentações de diversas pesquisas em andamento do mestrado em design da instituição, bem como, as pesquisas desenvolvidas nas duas instituições associadas no projeto. Essa experiência se mostrou de extrema importância para a difusão de estudos relativos ao design nas três regiões do Brasil, o nordeste representado pela UFMA, a região sudeste, através da participação da ED/UEMG e o sul do país com as pesquisas apresentadas pelos docentes da UFPR. Mais uma vez, foram várias as discussões frente a relação design-artesanato, haja vista que o PPGDg em design da UFMA, concentra forte pesquisa relacionadas às reflexões acerca dessa abordagem.

Outro evento de significativa contribuição foi o $7^{\circ}$ Simpósio de Design Sustentável, evento internacional que contribuiu para o aprofundamento do conhecimento sobre sustentabilidade. $\mathrm{O} 7^{\circ}$ SDS foi realizado na cidade de Recife-PE, entre os dias 11 a 14 de novembro de 2019, após o período de missão de estudos, no entanto a construção do artigo foi concretizado em missão.

A exposição sobre o designer, tipográfico e artista plástico mineiro Sebastião Nunes, também foi prestigiada no período. O evento ocorreu na nova Escola de Design, localizada na Praça da Liberdade, em Belo Horizonte - MG. Na ocasião, várias histórias do designer e artista, foram contadas através das suas produções expostas, demonstrando a importância da valorização de profissionais da terra, que se dedicam a evidenciar o valor do que é produzido no próprio estado.

Um dos principais eventos da missão de estudos foi a Semana de Pesquisa em Design (Figura 03). Evento promovido pela pós-graduação em design da ED/UEMG, realizando-se na nova Escola de Design, configurando-se como importante experiência, pois foi oportunizado ao pesquisador em missão, apresentar a pesquisa de mestrado, em construção, e os conhecimentos a respeito de teorias de design, artesanato, materiais (cerâmica) e sustentabilidade. Enfim, todos as vivências nos eventos e congressos participados, promoveram uma constituição de novos conhecimentos acerca do design, as suas relações multidisciplinares e as caracterizações de pesquisas desenvolvidas nas diferentes regiões do país. 
Figura 03: Participação na Semana de Pesquisa em Design da ED/UEMG

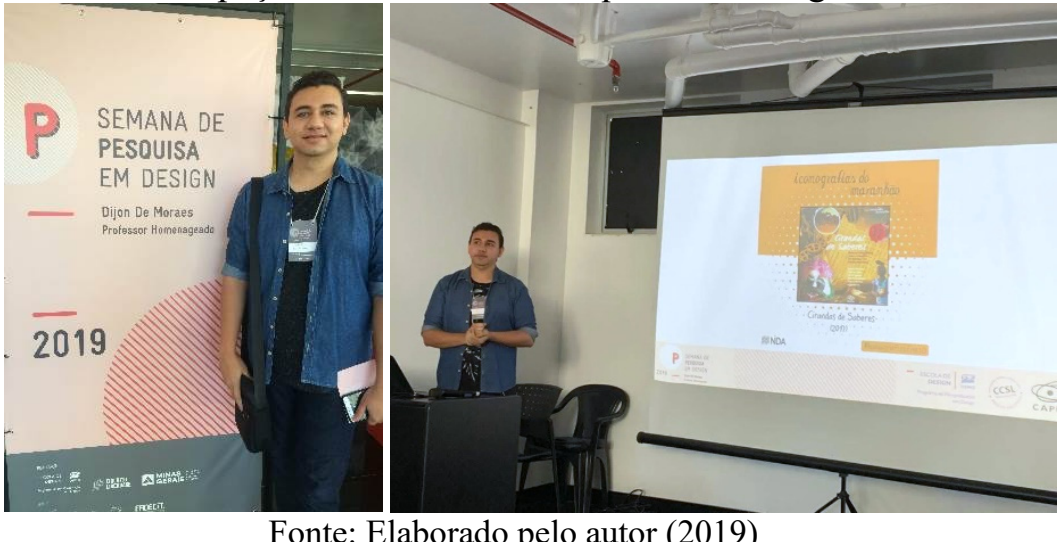

\subsection{Os Centros de pesquisa e as correlações ocorridas}

As contribuições dos Centros de pesquisa da ED/UEMG, foram primordiais para o descobrimento de novas possibilidades de estudos e da congregação, com os conhecimentos desenvolvidos no PPGDg UFMA.

O Centro de Estudos em Design e Tecnologia - CEDETec, foi apresentado pela Profa. Dra. Nadja Maria Mourão. Na ocasião a professora explanou sobre os vários projetos do centro de pesquisa e sobre sua tese de doutorado. Ainda no CEDETec, foram conhecidos outros docentes que desenvolvem pesquisas por meio dos fundamentos e bases do Design Anthropology - uma abordagem do design. Foi dialogado sobre as pesquisas realizadas pela Profa. Dra. Raquel Gomes Noronha da UFMA, que mergulha na mesma base de conhecimento. Uma observação importante a relatar é que a professora Raquel Noronha, se firma como referência, na área de estudo do centro de pesquisa da UEMG. O Centro de Estudos em Teoria, Cultura e Pesquisa em Design - T\&C Design, foi o centro de maior aproximação durante a missão de estudos. As oportunidades de trocas foram abertas pela Profa. Dra. Maria Regina Álvares Correia Dias, onde está se consolidou como orientadora do mestrando em missão, durante todo o período. Muitos foram os aprendizados no T\&C Design, através de várias conversas, compartilhamento de produção acadêmica e atividades práticas relacionadas a ações do centro.

Outros centros de pesquisa se mostraram importantes para o aprofundamento das relações e ampliação de conhecimento, durante a missão de estudos. Um deles foi o Centro de Estudos em Design de Gemas e Jóias - CEDGEM, coordenado pelo Prof. Dr. Adriano Mol, por meio do Laboratório de Cerâmica (Figura 04). Conhecer o laboratório, contribuiu para o fomento de novas ideias e possibilidades, no futuro, de projetos em parceria UFMA-ED/UEMG, pois a pesquisa do mestrando em missão, envolveu os conhecimento em design e materiais, especificamente os materiais cerâmicos. O Centro Integrado de Design Social, foi apresentado pelo seu coordenador, Prof. Dr. Edson Carpintero. Na ocasião o professor, apresentou suas pesquisas em desenvolvimento, bem como as já concluídas. Foram realizados, também orientações a respeito de metodologias e ferramentas de design, trabalhadas e aplicadas em pesquisas desenvolvidas no Centro Integrado de Design Social, além da apresentação de artigos científicos publicados, que abordaram a temática do design participativo e a relação entre design e artesanato, com o objetivo de entendermos melhor os métodos trabalhados pelo centro.

Figura 04: Visita ao Laboratório de Cerâmica na ED/UEMG
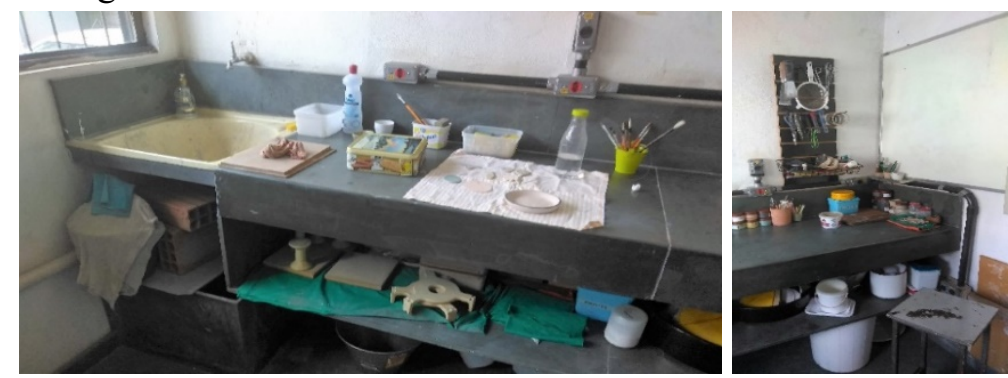

Fonte: Elaborado pelo autor (2019) 
O Centro de Design e Empresa, proporcionou conhecimentos relativos aos materiais, especificamente. A Profa. Dra. Caroline Pagnan, explanou sobre suas as pesquisas no centro, que envolvem o estudo de ensaios de materiais como ensaios químicos, mecânicos e físicos, realizados pela professora em suas pesquisas de mestrado e doutorado, bem como os materiais biopolímeros. Conhecer os centros de pesquisas da ED/UEMG, se configurou como uma vivência de expressiva importância, pelas oportunidades firmadas e por possibilitar um aprofundamento a respeito das atividades relativas à missão de estudos.

\subsection{A pesquisa de campo: ampliando os horizontes por meio de Belo Horizonte}

A experiência do intercâmbio de saberes, proporcionado pelas vivências em missão de estudos, foram fortificados e aprofundados através de várias idas a diferentes campos. Objetivou-se promover o entendimento sobre as práticas artesanais em cerâmica, possivelmente encontradas em diferentes cenários na cidade de Belo Horizonte - MG, no tentame de identificar as nuances entre os saberes artesanais em cerâmica que se apresenta no Maranhão e os possíveis cenários encontrados na capital mineira.

A pesquisa de campo de maior aproximação foi concretizada nas idas à Feira de Artes e Artesanato, acontecendo nas manhãs de domingo, na avenida Afonso Pena em Belo Horizonte - MG (Figura 05). Essa feira promove a venda de produtos regionais e não regionais (com menor frequência). Os produtos compreendem em móveis, roupas, calçados, artigos de decoração, utilitários, e muita diversidade de comidas típicas do estado de Minas Gerais. A primeira ida à feira, oportunizou conhecer suas características, além da busca prévia por produtos cerâmicos e por artesãos que trabalham com a produção artesanal em cerâmica. Como resultado, conversas foram realizadas com três artesãos que realizavam atividades artesanais em cerâmica, com foco na pintura e acabamento, logo foi estabelecido contatos e outras duas visitas a feira foram programadas.

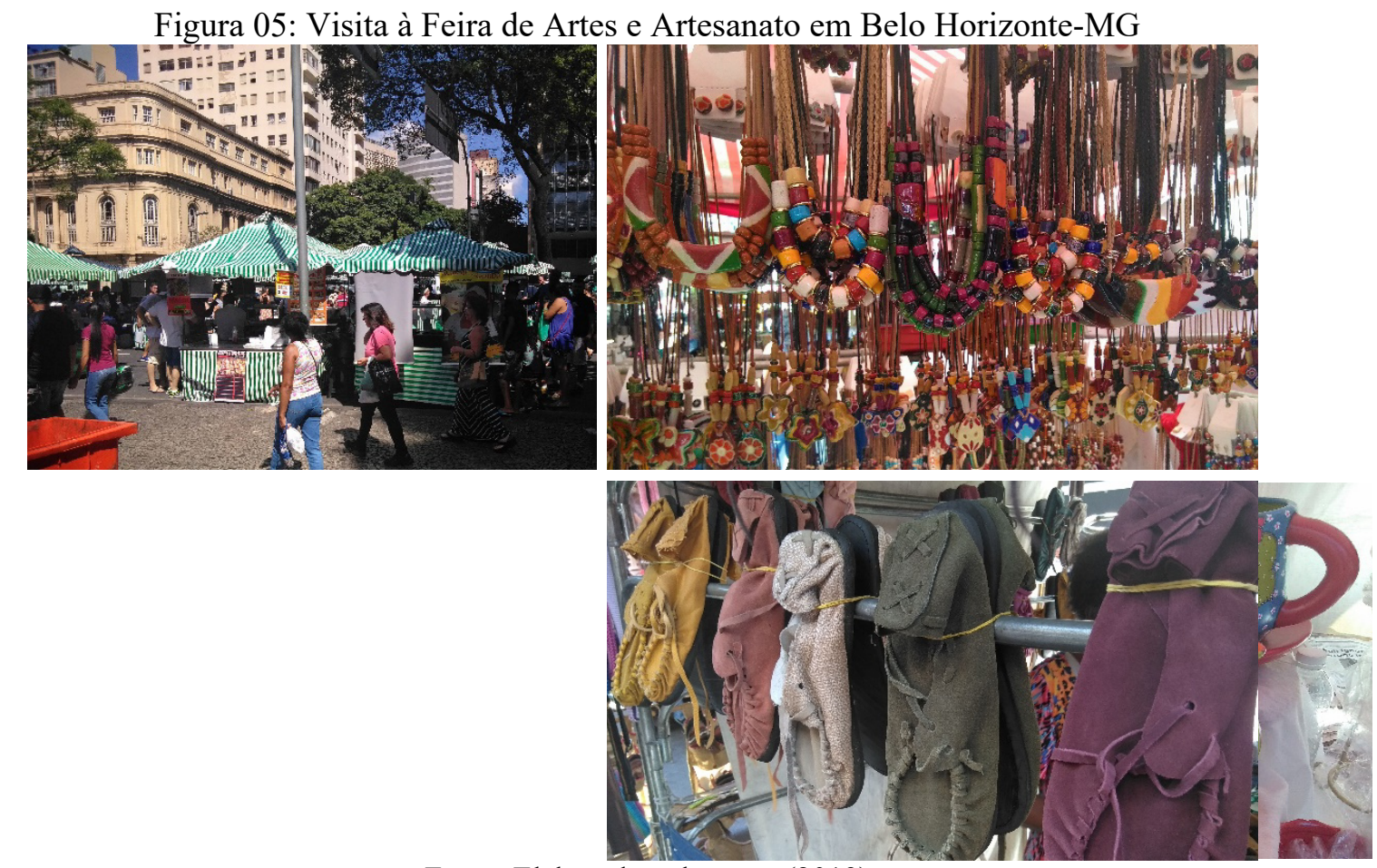

Fonte: Elaborado pelo autor (2019)

A segunda ida ao campo, na feira de artes e artesanato, estabeleceu um contato maior com os artesãos, promovendo informações melhor refletidas. Destaca-se que a feira se caracteriza como um espaço de venda de produtos artesanais, onde os próprios artesãos exercem a comercialização, em sua maioria. Portanto, a observação foi muito empregada nesse campo e os diálogos com os artesãos foram acontecendo, à medida que algum espaço de tempo foi sendo aproveitado, entre uma comercialização e outra. 
$\mathrm{Na}$ terceira ida ao campo da feira de artes e artesanato, o objetivo foi encontrar outros artesãos para dialogar sobre seus produtos e processos. Três foram as artesãs, na qual pode-se conversar e levantar informações. Todas utilizam peças já prontas de cerâmica branca, sem pinturas, vindas do estado de São Paulo. Em sua maioria as peças de cerâmica encontradas na feira, são todas provenientes de outros estados, onde se aplica em Minas Gerais, a técnica da pintura a frio - utilização de tintas plásticas - na superfície dessas peças. Na ocasião, uma exposição com peças artesanais do Vale do Jequitinhonha - MG, acontecia em paralelo a feira de artes e artesanato, no Centro Artesanato Mineiro.

A visita foi muito proveitosa, pois foram promovidos outros contatos com artesãos e suas peças artesanais em cerâmica, tradicionalmente produzidas no interior do estado de Minas Gerais. Uma outra curiosidade observada, relativa nessa experiência em campo, foi o fato do não encontro de peças cerâmicas da região do Vale do Jequitinhonha - MG com maior frequência, na feira. Nas buscas de estudos da literatura sobre cerâmica artesanal em Minas Gerais, é percebido o valor e identidade da cerâmica desenvolvida na região do Vale, no entanto nesta feira em Belo Horizonte, poucas foram as tendas que comercializam essas peças. Sendo que, segundo relatos dos artesãos, observados em campo, o estado de São Paulo se firma como principal fornecedor de peças cerâmicas, vendidas na feira.

Como última vivência em campo, durante a missão de estudos, e a convite da Dra. Maria Regina Álvares Correia Dias, o mestrando em missão, foi a feira de artesanato do Vale do Jequitinhonha promovida pela Universidade Federal de Minas Gerais - UFMG (Figura 06). Oportunidade de encontrar os mais diversificados produtos artesanais, sobretudo a cerâmica, produzidos na região do Jequitinhonha, região do interior de Minas Gerais que fica a $732 \mathrm{~km}$ da capital mineira. Os produtos compreendem em cestarias, tecelagem, carpintaria, biojóias, pinturas, cerâmica, que é o produto mais produzido no Vale, dentre outros.

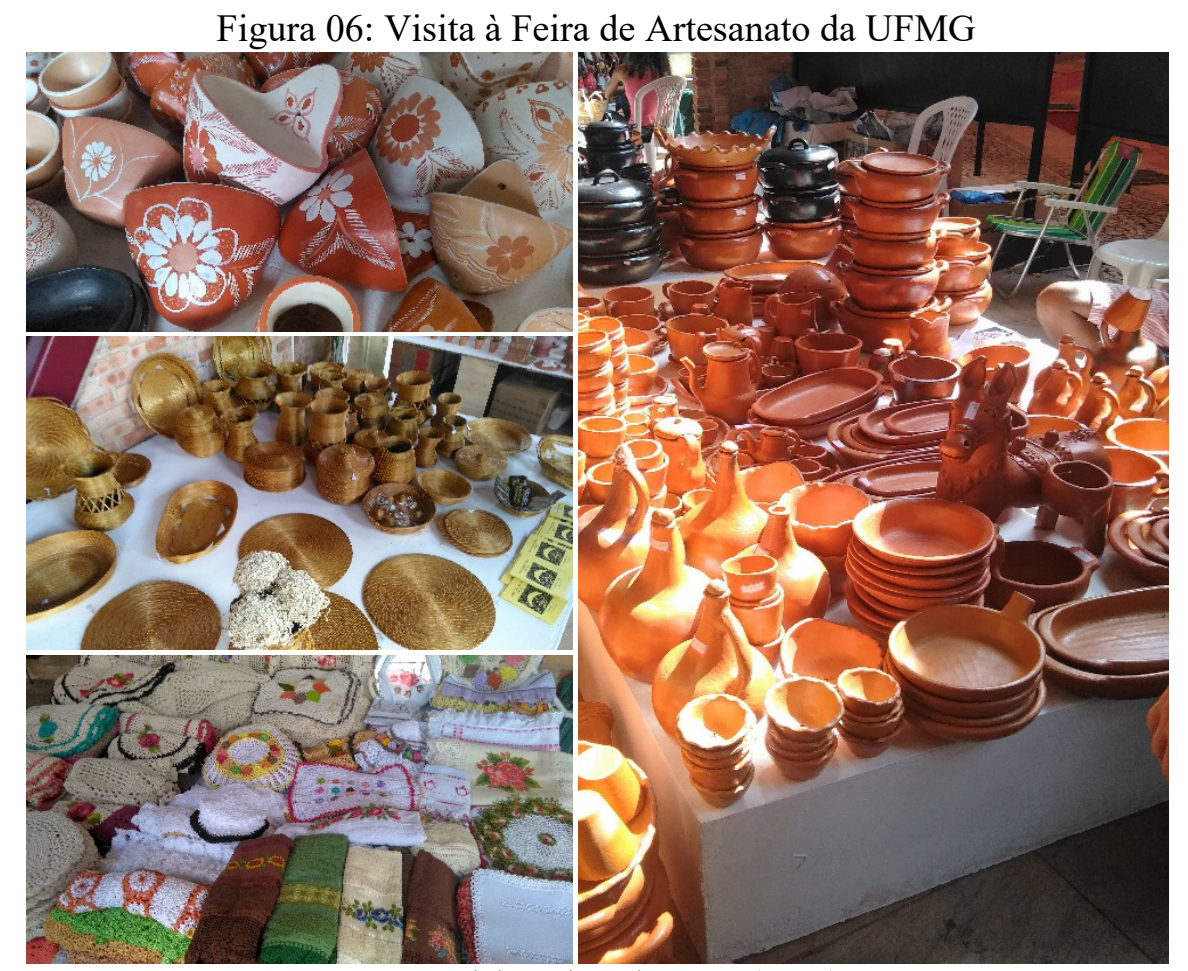

Fonte: Elaborado pelo autor (2019)

Logo buscou-se os produtos cerâmicos, foco da investigação científica na pesquisa de mestrado do discente em missão. Uma aproximação possível foi efetivada com um artesão mais conhecido na sua região como mestre Marcinho. $\mathrm{O}$ artesão apresentou suas produções, dentre elas esculturas em madeira e cerâmica, com cenas do cotidiano, feitos a partir de diversas técnicas (Figura 07). Suas peças, que estavam em exposição na feira na UFMA, não possuíam pinturas como técnica de acabamento, observou-se que a cor da cerâmica se apresentava bastante diferente. Como resposta o 
artesão comentou que a cor varia de acordo com a lenha empregada no forno para a queima, quando se queima com a lenha da aroeira (Myracrodruon urundeuva), por exemplo, a cor da cerâmica resulta em um tom amarelo escuro, sem a necessidade de pintura superficial. O mestre Marcinho explicou ainda que as outras cores, características da produção artesanal em cerâmica do Vale do Jequitinhonha, são conquistadas majoritariamente com materiais naturais, o vermelho, por exemplo, é conquistada através do barro vermelho, o preto é conquistado com a aplicação do carvão e o branco é conquistado através da aplicação da tabatinga.

Figura 07: Peças em cerâmica de artesão, encontrada na feira de artesanato da UFMG

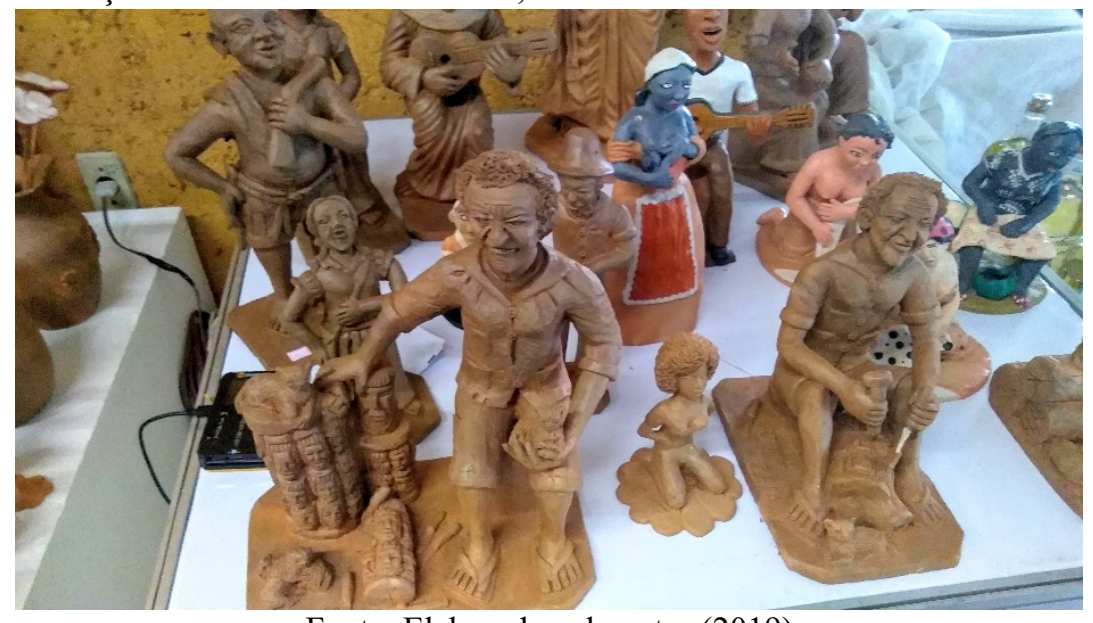

Fonte: Elaborada pelo autor (2019)

O artesão se mostrou uma pessoa extremamente cativante e, juntamente da sua esposa, podese dialogar e refletir sobre o grande universo da cerâmica na perspectiva da sua produção artesanal, revelando os diferentes processos em que trabalhava, tanto em cerâmica como em madeira. No final do diálogo surgiu a ideia de uma visita ao Vale do Jequitinhonha, onde haveria maior contato com outros artesãos da região, além de conhecer de perto os processos do mestre Marcinho. O próprio, mostrou-se empolgado com essa possibilidade, no entanto, essa ida ao campo não foi concretizada, devido à distância da região do Vale, em relação a capital mineira, além do tempo disponível para a finalização da missão de estudos.

Visivelmente, as idas aos campos em Belo Horizonte - MG, foram de extremo significado, para a compreensão dos saberes e fazeres em cerâmica na região, bem como as possíveis trocas em relação às abordagens e experiências, respectivos ao artesanato em cerâmica do estado do Maranhão. A relação design-artesanato foi entendida nos diferentes campos, sendo, especificamente, na feira promovida pela UFMG, um importante canal para uma maior interrelação entre esses dois agentes, designer e artesão.

Considerados também como campos, outras localidades foram visitadas. A cidade de Brumadinho - MG, através da ida ao Instituto Inhotim, a cidade de Ouro Preto - MG e Mariana - MG. Todas as cidades foram visitadas com o intuito de descobrir novos horizontes pelo interior do estado de Minas Gerais, na busca por produtos e/ou processos que possivelmente envolveriam os materiais estudados na missão, no caso os materiais cerâmicos, e também, como destinos turísticos a fim de contemplar as belezas do interior do estado de Minas.

\section{Considerações Possíveis: quais foram os ganhos?}

A interação entre todos é de fundamental importância para a boa condução dos trabalhos, onde se percebe que o ótimo relacionamento se caracteriza como fator facilitador da missão de estudo. Logo todos os docentes envolvidos no projeto Procad - Amazônia da ED/UEMG, para além, todos os professores, que obtive contato na instituição, promoveram uma excelente recepção. $O$ compartilhamento de informações foram de primordial importância para a difusão do conhecimento, pois sabe-se da importante característica multidisciplinar e transdisciplinar das abordagens do design. 
Outro ganho, se revelou no apoio dos discentes da pós-graduação em design da ED/UEMG, especialmente os alunos do doutorado que acompanharam as atividades, orientando sobre as possibilidades de estudos e disponibilizando informações sobre a cidade de Belo Horizonte. Várias foram as reflexões e vivências profissionais.

A apresentação dos centros, núcleos e laboratórios da ED/UEMG, se caracterizam como importante ganho no processo, no tocante ao conhecimento, abrangência e possibilidades de atuação em pesquisa e projetos, desenvolvidos por eles. Nesse sentido, nos primeiros dois meses de missão de estudos, foram oportunizados visitas em vários centros de pesquisa, dentre eles o Centro de Estudos em Design e Tecnologia - CEDETec, o Centro de Estudos em Design de Gemas e Jóias - CEDGEM, através do Laboratórios de Cerâmica e o Laboratório de Lapidação, o Centro de Estudos em Teoria, Cultura e Pesquisa em Design - T\&CDESIGN, o Centro Integrado de Design Social e o Centro de Design e Empresa - CDE, através do FAB LAB.

Nesses contatos, fora percebido que muitos projetos são voltados para uma linguagem de abordagem mais técnica na pesquisa em design, onde alguns estudos, envolvem a produção artesanal em um formato mais evidente, com foco nos produtos, cadeias produtivas, materiais e sustentabilidade. O resultado é positivo, sendo que todo o conhecimento apreendido, por meio das experiências vividas nessa missão de estudos, corroborou para o crescimento profissional, e acadêmico do discente em missão.

Um importante ganho na missão de estudos, foi o melhoramento do trabalho de dissertação mestrado, através das orientações de docentes da pós-graduação, em destaque as orientações da Profa. Dra. Maria Regina Álvares Correia Dias que desenvolveu um acompanhamento maior com o discente em missão. Esse fator foi de fundamental importância para o desenvolvimento da pesquisa, atrelada às orientações do professor orientador Prof. Dr. Denilson Moreira Santos da UFMA. Outra constatação de ganho positivo, foram os aprendizados conquistados na disciplina de Materiais Ecoeficientes, ministrado pela Profa. Dra. Rosemary, onde pode-se compreender ainda mais sobre os materiais, suas amplitudes, perspectivas dentro do design, além dos conhecimentos a respeito da sustentabilidade e a ecoeficiência. Destaca-se a importante participação da disciplina e da professora na missão de estudos na ED/UEMG, pois forneceu novos caminhos à produção científica, nacional e internacional e obtenção de orientações de extrema importância para a pesquisa no mestrado em design.

Reconhecer metodologias e possibilidades do design, processos e os exercícios do trabalho com materiais e cerâmica, além de desenvolver reflexões e lidar com pessoas entre docentes e discentes, para além, os artesãos, devido à troca proporcionada pelo projeto Procad/AM, se fez valorizar ainda mais, como pesquisador, todos os conhecimentos, tácitos e especializados, agregando novas referências e vivências na formação profissional. Compreende-se que a relação design-artesanato só tem a ganhar com a troca de experiência mútua, e particularmente essas vivências firmadas na ED/UEMG congregou ainda mais relevância no desenvolvimento acadêmico do discente em missão de estudos.

Em Minas Gerais, pode-se conhecer artesãos que proporcionaram o enriquecimento do conhecimento e valorização das experiências vividas. Perceber e lidar com as situações no dia-a-dia, avaliar e executar os estudos superando as adversidades, além de sempre ir em busca de resultados positivos, acrescem as experiências profissionais e elevam os anseios pessoais. A colaboração entre os professores, alunos e com outros pesquisadores do mestrado e doutorado, que trabalham em conjunto na troca de experiência, foram fatores enriquecedores, percebidos nas ações da missão.

\subsection{Relação entre um passado de "calmaria" e um presente de pandemia}

Aqui, retoma-se a indagação do início dessa comunicação: Como seria se a missão de estudos vivenciada, estivesse na sua instância, no olho do furacão? Pode-se ter como resposta a frustração em não oportunizar trocas tão intensas estabelecidas por vários atores sociais envolvidos nesses processos, promovidos pelo Procad/AM e construídos durante a missão de estudos. Seria como uma "clausura", onde existem um vasto universo e o máximo de aproximação possível se daria apenas em uma comunicação virtual, estando fisicamente em uma caixa de quatro paredes, possivelmente de blocos cerâmicos. Logo, justamente a cerâmica que serviriam para ampliar os horizontes, se postava de forma redutora e carcerária. Possibilitaria a não possibilidade dos encontros, fomentando um distanciamento forçado porém, entendido como necessário. 
Contudo, considera-se ser cada vez mais importante e urgente, a observância e valorização do meio em que habitamos, importa ter preocupação com o natural e os seus recursos, com o entendimento da sustentabilidade em todas por meio de todas as suas dimensões, além do valor do estar com o outro, da atenção dada as relações nas instâncias geracionais. Neste sentido, cabe relembrar que a relação design-artesanato, foi, ao longo da história, percorrendo caminhos de associações e dissociações. Importantes acontecimentos que desaguam, hoje, em um design que cada vez mais evolui e que apresenta outras teorias e formas de fazer design.

As relações próximas no período de pandemia, exatamente no olho do furacão, ou seja, no agora, são cada vez mais rememoradas, evidenciando a necessidade de se pensar, inclusive, em um design relacional com os materiais, com os outros seres, com os seres humanos e com o próprio conhecimento que se evolui, a partir dessas inter relações. Esse pensamento sobre as relações, fundamentalmente, precisa ser observado de forma diferente, sobretudo durante o período pandêmico e principalmente no "pós pandemia".

Enfim, experimentar vivências por meio do Procad/AM, sem a presença de "furacões", se mostrou de extrema importância para o desenvolvimento profissional e acadêmico, estimulando a difusão dos conhecimentos, sobretudo em design, além da compreensão de que formas de intercâmbio como esses, precisam continuar a ser distribuídas nas graduações e pós-graduações, por promover ganhos significativos na construção de pessoal mais qualificado, no design e em outras áreas do conhecimento.

\section{Experiences in Procad Study Mission: exchange of knowledge in design}

\section{Abstract:}

This article brings an experience report on participation in a mission of studies, through the Procad/AM project, related to the dissemination of knowledge in the field of design. In this sense, reflections are involved on the relationship between design and creative communities (crafts), focus of the approaches of this project and consequently the mission of studies, carried out in the associated institutions, in this case, the School of Design of the University of the State of Minas Gerais - ED /UEMG. Therefore, initially, reflections are presented about the relational establishment between the fields of design-crafts and the positioning of the designer, immersed in contexts of traditional communities. The course of the study mission at ED/UEMG, involved participation in disciplines and events in the area, literature review, partnership with research centers and field research implementation. It is anticipated that, the results of this interaction, enriched the students' experiences in mission, deepening knowledge, expanding opportunities, establishing possible futures on research, professional development and science.

Keywords: Design; Crafts; Procad/AM; Interaction 


\section{Referências Bibliográficas}

ALMEIDA, Henrique Bittencourt, $\mathbf{O}$ papel dos múltiplos atores no design para mudança de comportamento. 2018. 178 f. Dissertação (Mestrado) - Curso de Design, Universidade do Vale do Rio dos Sinos, Porto Alegre, 2018.

ARGAN, G. C. A História na Metodologia do Projeto. Revista Caramelo, São Paulo, no 6, p; 156-170, 1993

BINDER, Thomas et al. Design Things. Usa: Massachusetts Institute Of Technology, 2011

BORGES, Adélia. Design + Artesanato: o caminho brasileiro. São Paulo: Terceiro Nome, 2011.

CAPES, Coordenação de Aperfeiçoamento de Pessoal de Nível Superior. Programa Nacional de Cooperação Acadêmica (Procad). 2018. Disponível em:

https://www.capes.gov.br/bolsas/programas-estrategicos/formacao-de-recursos-humanos-em-areasestrategicas/programa-procad. Acesso em: 21 jul. 2020.

GAUDIO, Chiara del; OLIVEIRA, Alfredo Jefferson de; FRANZATO, Carlos. O tempo do design participativo. In: CONGRESSO BRASILEIRO DE PESQUISA E DESENVOLVIMENTO EM DESIGN, 11, 2014, Gramado. 110 P\&D Design. Gramado: P\&d 2011, 2014. p. 1 - 13.

LIMA, Marcela Fonseca. DESIGN E ARTESANATO: relações de poder. In: SIMPÓSIO DE DESIGN SUSTENTÁVEL, 5, 2015, Rio de Janeiro. Anais [...]. Rio de Janeiro: Blucher, 2015. p. 11-20.

MIRANDA, Samuel da Silva; SANTOS, Denilson Moreira; NORONHA, Raquel Gomes. Práticas Sustentáveis em Design Participativo. Blucher Design Proceedings, [s.I.], p. 664-672, out. 2019. Editora Blucher. http://dx.doi.org/10.5151/7dsd-3.2.060.

MIRANDA, Samuel da Silva. A tradição do punhado: avaliação da incorporação da cinza de taquipé (Triplaris sp.) em argila vermelha na produção artesanal. (Dissertação) - Mestrado em Design. Universidade Federal do Maranhão, São Luís, 2020.

MOURA, Elci Vieira de. AVALIAÇÃo DO PROGRAMA NACIONAL DE COOPERAÇÃo ACADÊMICA - PROCAD. 2016. 97 f. Tese (Doutorado) - Curso de Pós-Graduação em Educação em Ciências Química da Vida e Saúde, Universidade Federal do Rio Grande do Sul, Porto Alegre, 2016.

NORONHA, Raquel Gomes. Do centro ao meio: um novo lugar para o designer. In: CONGRESSO BRASILEIRO DE PESQUISA E DESENVOLVIMENTO EM DESIGN, 10, 2012, São Luís. Anais [...]. São Luís: P\&d, 2012. p. 01 - 3412.

NORONHA, Raquel Gomes et al. DESIGN, ARTESANATO E POLÍTICAS PÚBLICAS. In: JORNADA INTERNACIONAL DE POLÍTICAS PÚBLICAS, 7, 2015, São Luís. Anais [...]. São Luís: Edufma, 2015. p. 1-50. Disponível em: http://www.joinpp.ufma.br/jornadas/joinpp2015/pdfs/mesas/design-artesanatoe-politicas-publicas.pdf. Acesso em: 19 jul. 2020.

PORTELA, Raiama Lima. Correspondências por meio de ferramentas de design: artesanato e empoderamento (ou aprisionamento?). 2018. 130 f. Dissertação (Mestrado) - Curso de Design, Universidade Federal do Maranhão, São Luís, 2018.

RIBEIRO, Samyra dos Santos et al. Revestimento de parede com placas de circuito impresso de computadores e cerâmica: design e inovação. In: CONGRESSO BRASILEIRO DE PESQUISA E DESENVOLVIMENTO EM DESIGN, 11, 2014, Gramado. Anais [...]. Gramado: Ufma, 2014. p. 2 - 12.

SANTOS, Boaventura de S. Introdução a uma ciência pós-moderna. Porto: Afrontamento, 1989.

SPINUZZI, Clay. THE PARTICIPATORY DESIGN METHODOLOGY. Society for Technical Communication, Virginia, v. 2, n. 52, p.30-47, maio 2005. 